Arq. Bras. Med. Vet. Zootec., v.69, n.3, p.695-703, 2017

\title{
Utilização do yacon (Smallanthus sonchifolius) na proteção contra colonização intestinal de frangos de corte infectados por Salmonella Enteritidis
}

\author{
[Use of yacon (Smallanthus sonchifolius) protect against intestinal colonization of broilers \\ infectes by Salmonella Enteritidis]
}

\author{
M.G.X. Oliveira ${ }^{1}$, M.C. Porretta ${ }^{2,3}$, N.M. Itaya ${ }^{2,3,4}$, M.C.V. Oliveira ${ }^{1}$, J.N. Reple ${ }^{1}$, M.P.V. Cunha ${ }^{1}$, \\ L.A. Sanches ${ }^{1}$, Y.M. Davies $^{1}$, M.C. Menão ${ }^{4}$, J.C.S. Borges ${ }^{4}$, L.E.M. Polaquini ${ }^{4}$, T. Knöbl ${ }^{1 *}$ \\ ${ }^{1}$ Faculdade de Medicina Veterinária e Zootecnia - Universidade de São Paulo - São Paulo, SP \\ ${ }^{2}$ Faculdade de Ciências Biológicas - Complexo Educacional da Faculdades \\ Metropolitanas Unidas - FMU - São Paulo, SP. \\ ${ }^{3}$ Núcleo de Pesquisa em Fisiologia e Bioquímica - Instituto de Botânica \\ de São Paulo - IBT - São Paulo, SP \\ ${ }^{4}$ Faculdade de Medicina Veterinária - Complexo Educacional das Faculdades \\ Metropolitanas Unidas - FMU - São Paulo, SP
}

\begin{abstract}
RESUMO
Os frutanos do tipo inulina são oligossacarídeos que favorecem a multiplicação de determinados gêneros bacterianos no intestino, promovendo um efeito prebiótico. Este trabalho avaliou o efeito da inulina extraída de raízes de yacon (Smallanthus sonchifolius) sobre a colonização intestinal de frangos de corte experimentalmente infectados por Salmonella Enteritidis. Sessenta frangos de corte com um dia de idade foram divididos em três grupos de tratamento, com duas repetições, criados até 21 dias. As aves do grupo yacon receberam 100mg de inulina/dia, via oral, por três dias consecutivos. No sétimo dia de vida, as aves tratadas e o controle positivo foram desafiados pela via oral com uma cultura de $S$. Enteritidis. Não foram observadas diferenças de desempenho zootécnico entre os grupos. O índice de infectividade das aves suplementadas com yacon foi menor até o sexto dia após o desafio, mas, ao término do experimento, foi superior ao controle positivo. Os dados deste trabalho demonstram que o uso da inulina nos três primeiros dias de vida promoveu uma redução da colonização intestinal dos frangos por Salmonella Enteritidis na primeira semana após o desafio. Novos estudos são necessários para determinar a dose e o tempo de tratamento ideal para um efeito protetor de maior duração.
\end{abstract}

Palavras-chave: avicultura, inulina, prebióticos, Salmonella

\begin{abstract}
The fructan inulin-type oligosaccharides favor the multiplication of some bacterial genera in the intestine, promoting a prebiotic effect. This study evaluated the effect of inulin extracted from yacon roots (Smallanthus sonchifolius) on intestinal colonization of broilers experimentally infected with Salmonella Enteritidis. Sixty-one day old chicks were grouped into three treatments, with two replicates, and reared until 21 days. Birds in the yacon group received 100mg of inulin/day orally for three consecutive days. On the seventh day of life the treated birds and the positive control were challenged orally with a culture of S. Enteritidis. There were no differences between groups in live performance. The infectivity index of the chicks supplemented with yacon was lower until the sixth day after the challenge, but at the end of the experiment it was higher than the positive control. Data from this study show that the use of inulin during the first 3 days of life caused a reduction of intestinal colonization of chickens by Salmonella Enteritidis in the first week after challenge. Further studies are needed to determine the dose and the ideal time of treatment necessary for a longer protective effect.
\end{abstract}

Keywords: aviculture, inulin, prebiotcs, Salmonella

Recebido em 11 de fevereiro de 2015

Aceito em 9 de agosto de 2016

*Autor para correspondência (corresponding author)

E-mail: tknobl@usp.br

Apoio: FAPESP - Projeto IC (2012/25462-4) 


\section{INTRODUÇÃO}

A utilização de prebióticos nos sistemas de criação intensiva é uma boa alternativa para substituição do uso de aditivos medicamentosos, com reflexos positivos na avicultura (Barreto et al., 2008; Silva et al., 2011). Os prebióticos não têm um efeito direto sobre o desempenho zootécnico das aves, mas são capazes de promover uma melhoria da saúde intestinal, com a redução da carga patogênica decorrente do contato com agentes infecciosos (Godoi et al., 2008). Os prebióticos mais utilizados na alimentação animal são os oligossacarídeos, especialmente os mananoligossacarídeos (MOS), os frutoligossacarídeos (FOS) e os glucoligossacarídeos (GOS), que podem ser obtidos de vegetais, incluindo frutos e alguns tubérculos (Albino et al., 2006).

A utilização de FOS do tipo inulina como aditivo alimentar em aves de postura tem sido associada à diminuição dos níveis de triglicérides, colesterol sérico e gordura abdominal (De Los Santos e Turnes, 2005; Itaya et al., 2012). Entretanto, a principal vantagem do uso desses ingredientes fermentáveis seletivos está relacionada aos efeitos sobre a microbiota entérica, diminuindo a colonização intestinal por bactérias patogênicas. Bactérias com atividade probiótica são favorecidas pelo uso desses aditivos e se multiplicam, exercendo funções metabólicas e protetoras capazes de afetar positivamente a integridade da barreira intestinal (Lambert, 2009).

O yacon (Smallanthus sonchifolius) é uma espécie da família Asteraceae, que produz raízes tuberosas com sabor adocicado em razão da elevada quantidade de FOS. Dentre as inúmeras propriedades medicinais relacionadas à ingestão desta raiz, destaca-se o efeito prebiótico, uma vez que o carboidrato não digerível é capaz de favorecer a multiplicação de Bifidobacterium spp. no trato gastrointestinal (Rodrigues et al., 2011). Essa planta é originária dos vales andinos da Colômbia, do Equador, do Peru, da Bolívia e do noroeste da Argentina. É uma espécie de fácil cultivo e adaptação às variações de clima, altitude e solo. Apresenta alta resistência ao frio e à seca, em razão da elevada quantidade de carboidratos de reserva nos órgãos subterrâneos (Lost, 1989).
A raiz tuberosa de yacon é composta por inulinas e possui 40 a $70 \%$ de FOS em base seca. Os carboidratos pertencentes à classe dos frutanos não são degradados pela ação enzimática do estômago e do intestino delgado, participando do processo fermentativo no cólon por bactérias da microbiota com função bifidogênica. Além do efeito prebiótico, os frutanos reduzem a taxa de renovação da mucosa intestinal e estimulam o sistema imunológico do hospedeiro (Oliveira et al., 2009). A ação acidificante da fermentação desses compostos promove a exclusão de microrganismos patogênicos, como Salmonella spp. (Fuentes et al., 2012).

O objetivo deste trabalho foi avaliar os efeitos da suplementação oral com inulina extraída do yacon (Smallanthus sonchifolius) em aves desafiadas com Salmonella Enteritidis.

\section{MATERIAL E MÉTODOS}

Para o preparo do extrato de yacon, as raízes tuberosas foram lavadas em água corrente e autoclavadas por 20 minutos. Em seguida, foram homogeneizadas em liquidificador, submetidas à extração aquosa por $30 \mathrm{~min}$ a $60^{\circ} \mathrm{C}$ e filtradas em tecido de algodão. $\mathrm{O}$ material vegetal foi submetido ao processo de extração aquosa da inulina por duas vezes, segundo a metodologia adaptada de Pollock e Jones (1979). Os filtrados das duas extrações foram reunidos $\mathrm{e}$ concentrados em rotoevaporador.

$\mathrm{O}$ teor de frutose total, na forma livre $\mathrm{e}$ combinada, foi determinado colorimetricamente pelo método de antrona modificado, conforme descrito por Jermyn (1956), sendo as dosagens realizadas em triplicata, utilizando-se inulina de Helianthus tuberosus (Sigma) como padrão. Os extratos foram purificados e analisados qualitativamente por cromatografia líquida de alta resolução (HPAEC/PAD).

Alíquotas de extrato, padronizadas na concentração de $100 \mathrm{mg}$ de inulina/ML, foram armazenadas em freezer a $-20^{\circ} \mathrm{C}$ até o momento do experimento, quando foram descongeladas em banho-maria.

O experimento foi realizado no Centro Experimental de Patologia Aviária (Cepa) do Departamento de Patologia da Faculdade de Medicina Veterinária e Zootecnia - USP. O 
projeto foi aprovado pelo Comitê de Ética e Uso de Animais - CEUA (2607/2012). Foram utilizados 60 frangos de corte da linhagem Cobb, machos, com um dia de idade, alojados em galpão convencional, com cortinas para controle da temperatura, umidade e luminosidade. O galpão foi limpo, desinfetado com amônia quaternária e permaneceu em vazio sanitário por 21 dias, antes do experimento.

Os boxes foram preenchidos com cama de maravalha e identificados de acordo com os diferentes grupos experimentais. $\mathrm{Na}$ data de recepção, as aves foram pesadas e distribuídas de forma randômica, seguindo um padrão de homogeneidade, com densidade de dez animais por $\mathrm{m}^{2}$. Receberam ração inicial e água $a d$ libitum. Adotou-se manejo de campânulas e cortinas, a fim de garantir o conforto térmico e bem-estar das aves.

As 60 aves foram divididas em três grupos de 10 animais, com duas repetições por tratamento: controle positivo $(\mathrm{C}+)$, controle negativo $(\mathrm{C}-)$ e grupo yacon (GY). O GY recebeu, a partir do primeiro dia, $1 \mathrm{~mL}$ de extrato de yacon por dia, na concentração de $100 \mathrm{mg}$ de inulina/ave/dia, durante três dias consecutivos, por meio de gavagem. No sétimo dia de vida, os grupos GY e o C+ foram desafiados pela via oral com Salmonella Enteritidis, pela inoculação de $0,1 \mathrm{~mL}$ de caldo contendo $1,0 \times 10^{7} \mathrm{UFC} / \mathrm{mL}$. O grupo C- não recebeu yacon e não foi desafiado. O delineamento experimental está representado na Tab. 1.

Tabela 1. Delineamento experimental

\begin{tabular}{ccc} 
Grupos experimentais & $\begin{array}{c}\text { Data das intervenções } \\
\text { (idade das aves em dia) }\end{array}$ & Experimento \\
\hline GY & $1^{\circ}$ ao $3^{\circ}$ dia & $\begin{array}{c}\text { 1mL de caldo de yacon via oral } \\
\text { Desafio com } S \text {. Enteritidis } \\
\left(1,0 \times 10^{7} \mathrm{UFC} / \mathrm{mL}\right)\end{array}$ \\
$\mathrm{C}+\mathrm{e} \mathrm{GY}$ & $7^{\circ} \mathrm{dia}$ & Coleta de fezes \\
$\mathrm{C}+; \mathrm{GY} \mathrm{e} \mathrm{C}-$ & $21^{\circ}$ dia & Eutanásia e coleta dos cecos \\
\hline
\end{tabular}

Após o desafio, foram realizadas quatro coletas de fezes, durante o período de 21 dias, dos GY e C+ para se avaliar a excreção de Salmonella. As aves e a ração foram pesadas semanalmente para os cálculos de ganho de peso, consumo de ração e conversão alimentar. Os animais foram eutanasiados em câmara de $\mathrm{CO}_{2}$ aos 21 dias de idade, para a realização de necropsia e coleta dos cecos para exame bacteriológico.

O material coletado durante a criação (um grama de fezes) e após a eutanásia dos animais (cecos) foi incubado em $20 \mathrm{~mL}$ de caldo de tetrationato de sódio a $37^{\circ} \mathrm{C}$ por $48 \mathrm{~h}$. Após o período de incubação, o volume de $0,1 \mathrm{~mL}$ foi semeado na superfície de ágar XLD, com auxílio de alça de Drigalski, e novamente incubado a $37^{\circ} \mathrm{C}$ por $24-$ 48h. As colônias suspeitas (colônias negras em fundo vermelho) foram submetidas à série bioquímica, com posterior confirmação pelo teste de soroaglutinação rápida com antígeno somático (Probac®).

Os dados foram agrupados em tabelas para análise e interpretação do fator de proteção (índice de infectividade do grupo controle em relação ao grupo tratado) e comparação estatística entre os grupos. Realizou-se a comparação estatística entre os grupos pelo software SPSS base 9.0. Os grupos experimentais foram comparados por um teste não paramétrico Kruskal-Wallis, considerando significativos os valores de $\mathrm{P}<0,05$.

\section{RESULTADOS}

A análise quantitativa da inulina extraída de raízes tuberosas de Smalanthus sonchifolia (yacon), resultante de 2583 gramas de massa fresca, apresentou um total de 152,47 gramas de inulina em um volume de $360 \mathrm{~mL}$. A Fig. 1 demonstra os resultados da análise da cromatografia líquida de alta resolução dos carboidratos solúveis totais de Smallanthus sonchifolia. O perfil cromatográfico mostrou que frutose, sacarose e frutanos com GP $3-\leq 17$ estão presentes no extrato de yacon.

Após a administração da inulina, na concentração de $100 \mathrm{mg} / \mathrm{ave} / \mathrm{dia}$, não foram 
observadas diferenças estatisticamente significantes entre o grupo controle e o grupo tratado (GY) na avaliação dos índices zootécnicos (ganho de peso, consumo de ração e conversão alimentar), até a data final do experimento. Os dados zootécnicos estão representados na Tab. 2 .

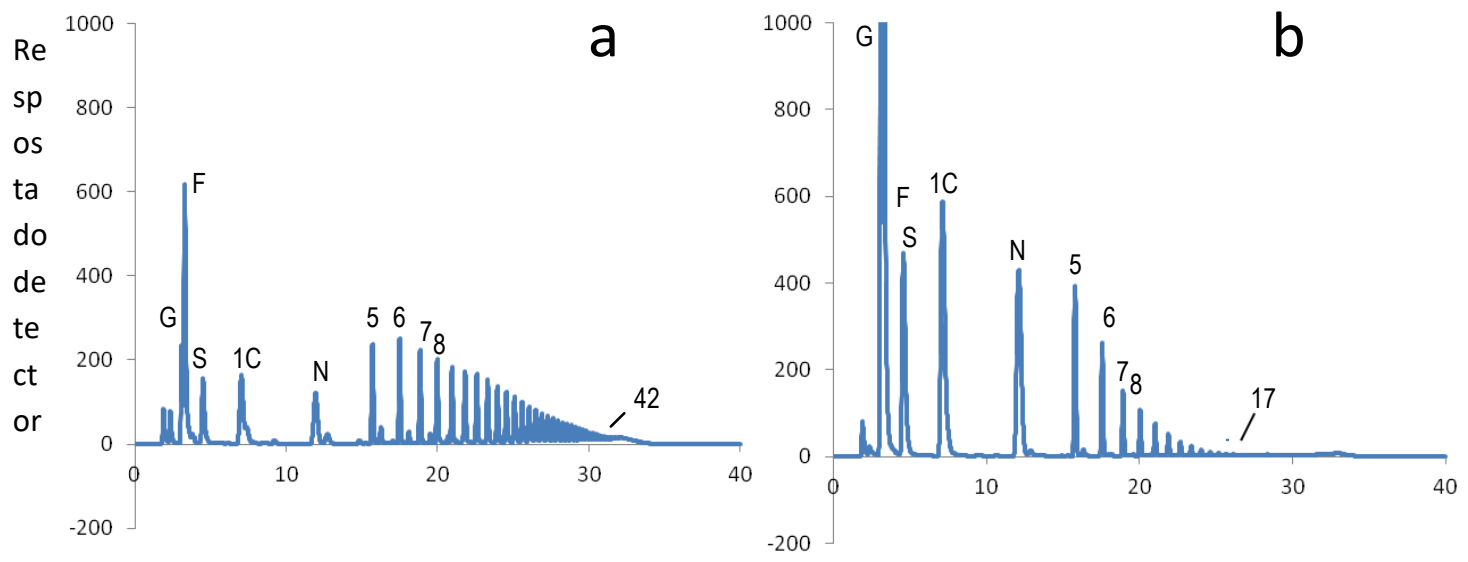

Tempo de eluição (min)

Figura 1. Análise por HPAEC/PAD em coluna CarboPac PA1 dos carboidratos solúveis totais do estrato bruto de Smallanthus sonchifolia (a). G, F, S, 1C e N referem-se aos tempos de eluição dos padrões de glicose, frutose, sacarose, 1-cestose e nistose, respectivamente. Os demais picos foram identificados por comparação com o tempo de eluição dos oligofrutanos de tubérculos de $H$. tuberosus (b). Os valores numéricos referem-se ao GP do frutano.

Tabela 2. Índices zootécnicos das aves tratadas com yacon, controle positivo e controle negativo, aos 21 dias

\begin{tabular}{cccc}
\hline Grupos & Ganho de peso $(\mathrm{g})$ & Consumo de ração $(\mathrm{g})$ & Conversão alimentar \\
\hline C+ & 746,000 & $1.370,800$ & 1,837533512 \\
C+ & 558,300 & $1.209,900$ & 2,167114455 \\
GY & 725,200 & $1.262,600$ & 1,741036955 \\
GY & 661,400 & $1.203,600$ & 1,819776232 \\
C- & 724,600 & $1.267,900$ & 1,749792989 \\
C- & 680,700 & $1.211,900$ & 1,780373145 \\
\hline
\end{tabular}

Foram analisadas 160 amostras de fezes coletadas das aves vivas, procedentes de coletas após o desafio, e 60 amostras obtidas da coleta dos cecos aos 21 dias, após a eutanásia dos frangos (quinta coleta). Nenhuma ave foi positiva no controle negativo. Os dados de isolamento do controle positivo $(\mathrm{C}+)$ e do grupo tratado com yacon $(\mathrm{GY})$ estão representados na Tab. 3 .

A Fig. 2 demonstra o padrão de excreção de Salmonella Enteritidis, após o desafio, das duas repetições dos grupos yacon (verde), controle positivo (vermelho) e controle negativo (azul), do segundo ao $21^{\circ}$ dia de vida das aves.
A infectividade do grupo tratado com yacon foi inferior, se comparada à do grupo controle positivo na primeira semana (até a terceira coleta), nas duas repetições. No entanto, na segunda semana após o desafio (quarta coleta), observou-se um aumento do número de aves infectadas nas duas repetições tratadas com yacon e, ao mesmo tempo, houve diminuição do número de aves infectadas nas repetições do controle positivo. Ao término do experimento (quinta coleta), o número de aves infectadas no $\mathrm{GY}$ foi superior ao $\mathrm{C}+$. 
Tabela 3. Resultados do exame bacteriológico das aves após o desafio com Salmonella Enteritidis

\begin{tabular}{cccccc} 
Coleta & $\begin{array}{c}\text { Idade das } \\
\text { aves (dias) }\end{array}$ & $\begin{array}{c}\text { Dias após desafio } \\
\text { com } S \text {. Enteritidis }\end{array}$ & Material & $\begin{array}{c}\text { C }+ \\
\text { infectadas/total }\end{array}$ & $\begin{array}{c}\text { GY } \\
\text { infectadas/total }\end{array}$ \\
\hline $1^{\mathrm{a}}$ & 9 & 2 & fezes & $11 / 20$ & $06 / 20$ \\
$2^{\mathrm{a}}$ & 11 & 4 & fezes & $08 / 20$ & $06 / 20$ \\
$3^{\mathrm{a}}$ & 13 & 6 & fezes & $14 / 20$ & $06 / 20$ \\
$4^{\mathrm{a}}$ & 15 & 8 & fezes & $13 / 20$ & $16 / 20$ \\
$5^{\mathrm{a}}$ & 21 & 14 & cecos & $09 / 20$ & $15 / 20$ \\
\hline
\end{tabular}

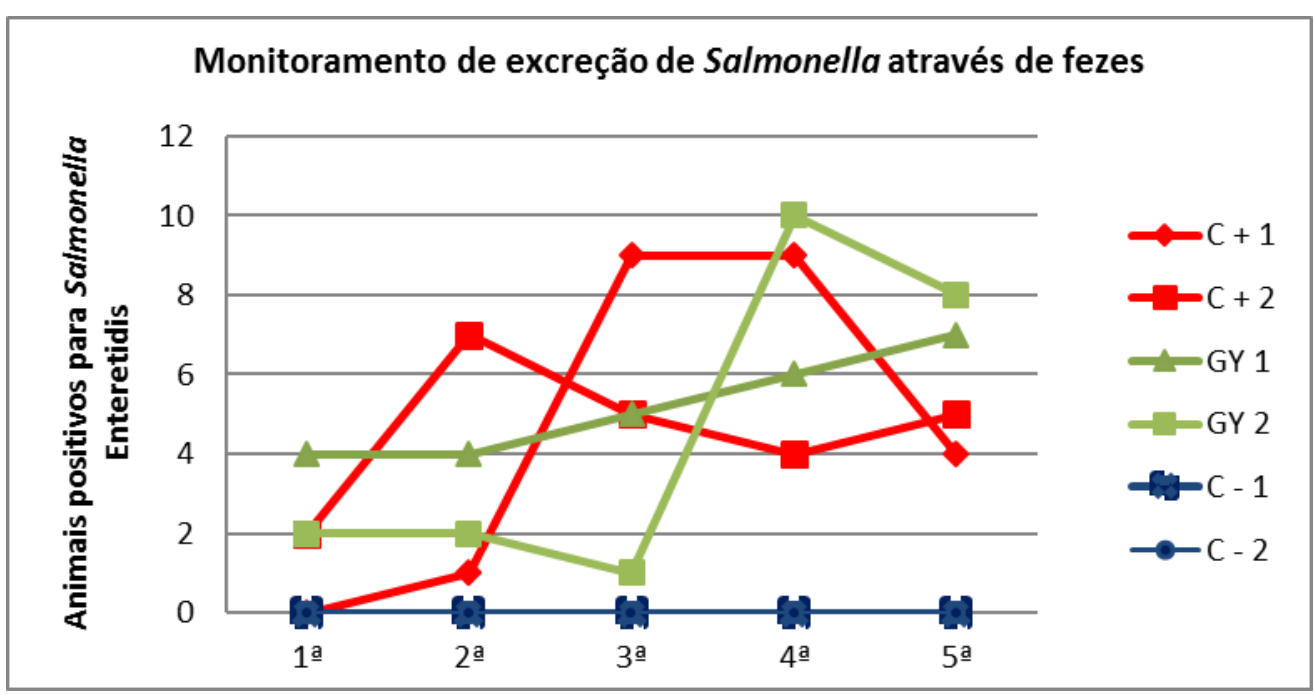

Figura 2. Isolamento de Salmonella Enteritidis das fezes de frangos inoculados experimentalmente. $\mathrm{C}+$ (controle +). C- (controle negativo). CY (tratados com yacon).

\section{DISCUSSÃO}

A utilização de prebióticos e probióticos na indústria e na produção animal com a finalidade preventiva é promissora e tem estimulado estudos científicos de inclusão desses componentes na alimentação animal (Rossi et al., 2007; Barreto et al., 2008). No entanto, os resultados dos experimentos são, ainda, contraditórios, e muitas lacunas precisam ser esclarecidas. Fuentes et al. (2012) foram os primeiros autores a utilizarem o yacon em seu delineamento experimental, incorporando o frutano por meio da adição de farinha na concentração de $0,75 \%$ na ração de engorda de patos no Peru. Os autores demonstraram que a adição de yacon representa um benefício nutricional, pois melhora os índices zootécnicos das aves. No entanto, os autores não realizaram ensaios de exclusão competitiva de patógenos.

Apesar da excelência comercial, a avicultura brasileira ainda encontra alguns desafios, como o controle das salmoneloses (Rodrigues, 2005;
Penha et al., 2008). No presente experimento, a opção por desafiar as aves com Salmonella Enteritidis reflete uma preocupação de saúde pública, uma vez que tal agente possui caráter zoonótico, além de afetar economicamente a produção avícola.

Um estudo anterior realizado pelo grupo de pesquisa do presente trabalho demonstrou que a suplementação da dieta de frangos de corte com extrato bruto de yacon durante todo o período de criação reduziu a infectividade da Salmonella Kedougou de $65 \%$ para $25 \%$ (Oliveira et al., 2013). No entanto, neste primeiro experimento, não foi possível dosar a quantidade de inulina administrada para cada ave, o que tornou seu uso empírico. A utilização do composto na forma de extrato bruto também teve um efeito negativo sobre o desempenho zootécnico das aves, que apresentaram diarreia após o terceiro dia de tratamento. É bastante provável que a quantidade de fibras vegetais presentes na formulação inicial tenha colaborado para esses aspectos negativos. Zatari et al. (1990) e Pinheiro et al. (2002) 
verificaram que a quantidade de fibras resultantes da adição de farelo de girassol piora a conversão alimentar dos frangos aos 28 dias de idade, devido ao aumento da taxa de passagem de digesta no trato gastrointestinal, com consequente redução no aproveitamento dos nutrientes.

Apesar da melhor viabilidade da introdução do prebiótico em forma peletizada ou de farinha, neste experimento optou-se pela administração da inulina na forma líquida, após a sua extração e quantificação, visando à redução da quantidade de fibras presentes nos produtos prebióticos, e assim obteve-se melhor controle da dose de frutanos fornecida a cada animal. O método de extração empregado foi eficaz e apresentou um rendimento considerável de frutanos, permitindo a administração de doses de $100 \mathrm{mg} /$ ave/dia. Não existem estudos anteriores sobre doses de inulina extraída do yacon para aves, e, desse modo, não há uma recomendação ou referência sobre a quantidade e/ou duração do tratamento.

A inulina na forma líquida utilizada neste experimento não influenciou negativamente o desenvolvimento dos animais, e as diferenças na conversão alimentar entre os grupos, mensurada semanalmente durante os 21 dias (Tab. 2), foi considerada semelhante, sob o ponto de vista estatístico. Nenhuma ave apresentou sinais clínicos sugestivos da ineficiência do frutano. No entanto, a inclusão da inulina extraída do yacon na dieta dos frangos de corte, nas condições testadas, foi ineficaz na proteção contra o desafio com Salmonella Enteritidis, na segunda semana de vida. $O$ fator de infectividade nos grupos suplementados foi menor na fase inicial do desafio, mas aumentou na segunda semana após a infecção e foi considerado estatisticamente não significativo $(\mathrm{P}<0,05)$ na comparação entre os grupos.

Verdonk et al. (2005) reforçam a hipótese de que a ação protetora dos prebióticos, bem como a resistência a infecções, varia conforme o tipo e a dose de inulina para cada espécie, assim como a virulência e a patogenicidade do agente investigado. É possível observar, nos resultados do experimento (Tab. 3), que o número total de aves infectadas foi menor no tratamento com a inulina extraída do yacon (Smallanthus sonchifolius) até os 13 dias de idade, o que corresponde ao sexto dia após o desafio.
Os resultados revelam que o poder de proteção contra infecção por Salmonella Enteritidis é responsivo na fase inicial do desafio, porém não impediu que o agente fosse eliminado pelas fezes. A avaliação do número de animais infectados nos diferentes grupos e repetições não segue um padrão homogêneo de distribuição (Fig. 2), mas, de modo geral, observou-se menor número de aves excretando o agente nos grupos tratados com yacon até a terceira coleta (sexto dia após infecção). Na quarta coleta, houve um aumento do número de aves com excreção do agente no GY, que pode ser resultado da transmissão horizontal entre as aves. Esse aumento também é evidenciado aos 21 dias, na análise das fezes coletadas diretamente dos cecos do GY (quinta coleta). Na segunda semana após a infecção, o número de aves positivas na cultura para Salmonella Enteritidis no $\mathrm{C}+$ diminuiu, provavelmente em razão da resposta imunológica das aves perante o agente.

A complexidade do ambiente intestinal e a interação entre hospedeiro, patógeno e ambiente dificultam a interpretação dos resultados, pois não há como impedir a transmissão horizontal no ambiente de criação. No presente trabalho, os animais excretaram o agente em suas fezes durante todo o experimento, mas em menor quantidade de UFC (unidades formadoras de colônias) na fase inicial do grupo tratado e maior número de UFC no controle positivo (dados não apresentados). Uma análise quantitativa por PCR em tempo real de aves criadas em isoladores poderá determinar diferenças quantitativas importantes entre os grupos, em estudos futuros. É possível que tenha ocorrido exclusão competitiva da microbiota em relação ao agente patogênico nos dias em que o produto foi administrado e que os resultados sejam promissores em um novo delineamento experimental, com um tempo de tratamento prolongado e/ou associação com uma cultura probiótica.

Além da transmissão horizontal, outra hipótese que justifica o aumento do número de aves infectadas na segunda metade do experimento, fato não observado nos ensaios com $S$. Kedougou, é a adaptação do sorovar $S$. Enteritidis ao ambiente ácido, promovida pela fermentação das bactérias probióticas. Lound et al. (2011) realizaram um experimento sobre a resistência a ácido e à temperatura de sorotipos 
de Salmonella em albumina de ovo desidratada e constataram que, entre os sorovares estudados, $S$. Enteritidis e $S$. Typhimurium mostraram maior resistência aos efeitos do $\mathrm{pH}$ abaixo de 5 .

Paz et al. (2010) avaliaram os efeitos de diferentes aditivos promotores de crescimento em dietas de frangos de corte de um a 10 dias de idade e relataram que pequenas diferenças no índice de infectividade podem estar relacionadas ao efeito imunomodulador, decorrentes do controle de temperatura, umidade e condições de manejo do experimento.

Salmonella possui capacidade de adesão e invasão, o que a caracteriza como uma bactéria intracelular com mecanismos para driblar o sistema imunológico, resistindo à ação bactericida nos fagócitos (Little et al., 2004). Uma pesquisa realizada por Babu et al. (2012) relacionou os efeitos das inulinas de frutoligossacarídeos na expressão de genes inflamatórios em macrófagos de frangos (in vitro) e a morte de Salmonella, sugerindo que a ação do prebiótico na prevenção à infecção se deva à expressão de linhagens de macrófagos HD11. Entretanto, os autores não comprovaram a eficiência da inulina na redução da carga patogênica, necessitando de novos estudos in vivo. Estudos com frutoligossacarídeos comerciais propuseram que a sua administração pode regular a secreção de $\operatorname{IgA}$ em ratos jovens, sugerindo ser um tratamento mais eficaz para prevenir a infecção por $S$. Typhimurium em suínos (Nakamura et al., 2004; Letellier et al., 2000).

Rish et al. (2009) relataram que a administração de inulina é capaz de evitar danos hepáticos em ratos desafiados, impedindo a translocação do patógeno. Além dessas propriedades, Bibas et al. (2010) descobriram que a farinha da raiz yacon, quando administrada por um longo período de tempo, aumenta o número de bifidobactérias e lactobacilos no intestino grosso de ratos, e esses microrganismos exercem um efeito imunomodulador, ocasionando a elevação de células IgA, células T, IL-10 e outras citocinas.

Velez et al. (2013) utilizaram camundongos como modelo experimental e observaram maior proteção contra $S$. Typhimurium após a administração por 30 dias de $340 \mathrm{mg} / \mathrm{kg}$ de farinha de yacon. Os autores atribuem o efeito protetor à alta produção de imunoglobulinas nas mucosas $(\operatorname{Ig} \mathrm{A})$. Esse indicativo remete aos estudos sobre proteção exercida pela farinha da raiz yacon contra o patógeno, uma vez que a elevada taxa de IgA não específica (S-IgA) evitaria a internalização do patógeno e os complexos imunes seriam eliminados por meio de peristaltismo (Lamm et al., 1996).

\section{CONCLUSÕES}

Os dados deste trabalho demonstraram que a administração de inulina extraída de yacon (Smallanthus sonchifolius) na dose de 100mg/ave, por via oral, nos três primeiros dias de vida, não influenciou o desempenho zootécnico de frangos de corte até o $21^{\circ}$ dia de idade. Os animais tratados apresentaram-se clinicamente saudáveis e sem sinais de diarreia após a ingestão do produto. A suplementação da dieta com yacon nas condições experimentais descritas reduziu o número de aves com excreção fecal de Salmonella Enteritidis na primeira semana após o desafio, mas não impediu a colonização intestinal de frangos de corte. É importante que haja novos estudos para determinar a dose e o tempo de tratamento necessário para uma proteção mais efetiva. A associação do prebiótico com probióticos bem como os efeitos imunomoduladores podem ser investigados em experimentos futuros.

\section{REFERÊNCIAS}

ALBINO, L.F.T.; FERES, F.A.; DIONIZIO, M.A. et al. Uso de prebióticos à base de mananoligossacarídeo em rações para frangos de corte. Rev. Bras. Zootec., v.35, p.742-749, 2006.

BABU, U.S.; SOMMERS, K.; HARRISON, L.M.; BALAN, K.V. Effects of fructooligosaccharide-inulin on Salmonellakilling and inflammatory gene expression in chicken macrophages. Vet. Immunol. Immunopathol., v.149, p.92-96, 2012.

BARRETO, M.S.R.; MENTEN, J.F.M.; RACANICCI, A.M.C. et al. Plant extracts used as growth promoters in broilers. Braz. J. Poult. Sci., v.10, p.109-115, 2008. 
BIBAS B.M.; MORENO, L.A.; DOGI, A. Prebiotic effect of yacon (Smallanthus sonchifolius) on intestinal mucosa using a mouse model. Food Agric. Immunol., v.21, p.175-189, 2010.

DE LOS SANTOS, J.R.G.; TURNES, C.G. Probióticos em avicultura. Cienc. Rural, v.35, p.741-747, 2005.

FUENTES, N.N.; FIGUEROA, E.T.; CARCELÉN, F.C.; ARBAIZA, T.F. Harina de yacón (Smallanthus sonchifolius) como probiótico em dieta de patos muscovy (Cairina moschata) em etapa de engorde. Rev. Investig. Vet. Peru., v.23, p.105-111, 2012.

GODOI, M.J.S.; ALBINO, L.F.T.; ROSTAGNO, H.S. et al. Utilização de aditivos em rações formuladas com milho normal e de baixa qualidade para frangos de corte. Rev. Bras. Zootec., v.37, p.1005-1011, 2008.

ITAYA, N.M.; BORGES, J.C.S.; MENÃO, M.C. et al. Efeito prebiótico da inulina extraída da Bardana (Arctium lappa) em aves comerciais: proteção contra a colonização por Salmonella. In: CONGRESSO LATINO AMERICANO DE MICROBIOLOGIA-ALAM, 21., 2012, Santos. Anais... Santos: FMVZ-USP, 2012. p.106. (Resumo).

JERMYN, M.A. A new method for the determination of ketohexoses in presence of aldohexoses. Nature, v.177, p.38-39, 1956.

LAMBERT, G.P. Stress-induced gastrointestinal barrier dysfunction and its inflammatory effects. J. Anim. Sci., v.87, p.101-108, 2009.

LAMM, M.; NEDRUG, J.G.; KAETZEL, C.S. et al. New insight into epithelial cell function in mucosal immunity: neutralization of intracellular pathogens and excretion of antigens by IgA. In: KAGNOFF, M.; KIYONO, H. (Eds.). Essentials of mucosal immunology. San Diego: Academic Press, 1996. Cap.12. p.141-150

LETELLIER, A.; MESSIER, S.; LESSARD, L. Assessment of various treatments to reduce carriage of salmonella in swine. Can. J. Vet. Res., v.64, p.27-31, 2000.

LITTLE, C.L.; SURMAN-LEE, S.; GREENWOOD, M. et al. Public health investigations of Salmonella enteritidis in catering raw shell eggs. Lett. Appl. Microbiol., v.44, p.595-601, 2004.
LOST crops of the incas: little-konwn plants of the Andes with promise for worldwide cultivation. Washington: Academy Press/NRC, 1989. 415p.

LOUND, S.; PLEM, L.F.; GENARO, F.; MARTINEZ, L.G. Resistência a ácido e a temperatura de sorotipos de Salmonella em albumina de ovo desidratada. In: LATIN AMERICAN POULTRY CONGRESS, 22., 2011, Buenos Aires. Proceedings... Buenos Aires: World Poultry, 2011. Disponível em: <http://pt.engormix.com/MAavicultura/saude/artigos/sorotipos-salmonellaalbumina-de-ovo-t674/165-p0.htm> Acessado em: 24 dez. 2013.

NAKAMURA, Y.; NOSAKA, S.; SUZUKI, M. Dietary fructooligosaccharides up-regulate immunoglobulin a response and polymeric immunoglobulin receptor expression in intestines of infant mice. Clin. Exp. Immunol., v.137, p.52$58,2004$.

OLIVEIRA, M.G.X.; ITAYA, N.M.; OLIVEIRA, M.C.V. et al. Utilização do yacon (Smallanthus sonchifolius) na proteção contra a colonização intestinal de frangos de corte, experimentalmente infectados por Salmonella spp. In: CONGRESSO BRASILEIRO DE MICROBIOLOGIA, 27., 2013, Natal. Anais... Natal: Congresso Brasileiro de Microbiologia, 2013. p.208. (Resumo).

OLIVEIRA, V.F.; ITAYA, N.M.; FLOH, E.I.S.; CARVALHO, M.A.M. Frutanos em calos de Smallanthus sonchifolius (Poepp.) H. Rob. Hoehnea, v.36, p.89-97, 2009.

PAZ, A.S.; ABREU, R.D.; COSTA, M.C.M.M. et al. Aditivos promotores de crescimento na alimentação de frangos de corte. Rev. Bras. Saúde Prod. Anim., v.11, p.395-402, 2010.

PENHA, G.A.; SUZUKI, E.Y.; UEDA, F.S.; PEREIRA, R.E.P. Diagnóstico da salmonelose e sua importância para a avicultura: revisão de literatura. Rev. Cient. Eletr. Med. Vet., v.6, p.1-8, 2008.

PINHEIRO, J.W.; FONSECA, N.A.N.; SILVA, C.A. et al. Farelo de girassol na alimentação de frangos de corte em diferentes fases de desenvolvimento. Rev. Bras. Zootec., v.31, p.1418-1425, 2002. 
POLLOCK, C.J.; JONES, T. Seasonal patterns oh fructan metabolism in forage grasses. New Phytol., v.83, p.9-15, 1979.

RISHI, P.; MAVI, S.K.; BHARRHAN, S. Protective efficacy of probiotic alone or in conjunction with a prebiotic in Salmonellainduced liver damage. FEMS Microbiol. Ecol., v.69, p.222-230, 2009.

RODRIGUES, D.P. Ecologia e prevalência de Salmonella spp. em aves e material avícola do Brasil. In: CONFERENCIA APINCO DE CIENCIA E TECNOLOGIA AVICOLA. Santos, 2005. Anais... Santos: [s.n.], 2005. p.223-228.

RODRIGUES, F.C.; CASTRO, A.S.B.; MARTINO, H.S.D.; FERREIRA, C.L.L.F. Farinha de yacon (Smallanthus sonchifolius): produção e caracterização química. Rev. Inst. Adolfo Lutz, v.70, p.290-295, 2011.

ROSSI, A.A.; PADILHA, M.T.S.; SANTOS, I.I.; PADILHA, J.C.F. Uso de probiótico na prevenção de salmoneloses em frangos de corte. Cienc. Agrotec., v.31, p.207-1211, 2007.
SILVA, M.W.T.; NUNES, R.V.; POZA, P.C. et al. Avaliação de inulina e probiótico para frangos de corte. Acta Sci. Anim. Sci., v.33, p.19-24, 2011.

VELEZ, E; CASTILLO, N.; MESO`N, O. et al. Study of the effect exerted by fructo-oligosaccharides from yacon (Smallanthus sonchifolius) root flour in an intestinal infection model with Salmonella typhimurium. Br. J. Nutr., v.109, p.1971-1979, 2013.

VERDONK, J.M.A.J.; SHIM, S.B.; LEEUWEN, P.V.; VERSTEGEN, M.W.A. Application of inulin-type fructans in animal feed and pet food. Br. J. Nutr., v.93, p.125-138, 2005.

ZATARI, I.M.; SARDINAS, O; GARCIA, J.A. The utilization of $20 \%$ sunflower seed meal in broiler chickens. Poult. Sci., v.69, p.1503-1507, 1990. 